Quebec Cooperative Study of

Friedreich's Ataxia

\title{
Pulmonary Function Studies in Friedreich's Ataxia
}

\author{
M. A. BUREAU, P. NGASSAM, B. LEMIEUX, AND A. TRIAS
}

SUMMARY: Pulmonary function tests were carried out on 20 patients with Friedreich's ataxia. The lang volume, diffusing capacity, flow rate, flowvolume curve, and blood gases were measured. In each patient the degree of scoliosis was measured and the pulmonary function tests were analyzed in relation to the scoliosis. A control group of 13 subjects with idiopathic scoliosis was used for comparison. In both groups, the degree of scoliosis was similar.

RÉSUME: Nous avons évalué la fonction pulmonaire de 20 patients atteints de l'ataxie de Friedreich. Les capacités pulmonaires, la capacité de diffusion. les débits, la courbe débit-volume et les gaz artériels ont été mesurés. Nous avons calcule pour chaque patient, le degré de scoliose et les résultats des tests obtenus one été analysés en relation avec celui-ci. Pour fin de comparaison, les tests de fonction pulmonaire ont été mesurés chez 13 sujets porteurs de scoliose idiopathique de degré comparable. Les résultats démontrent premièrement, que la détérioration des fonctions pulmonaires est proportionnelle à la progression de la scoliose et, deuxièmement, que les pèrturbations physiologiques sont comparables dans les deux groupes.

From the Centre Hospitalier de l'Université de Sherbrooke.

Reprint requests for the complete supplement on Friedreich's ataxia to: Dr. André Barbeau. Clinical Research Institute of Montreal, 110 Pine Avenue West, Montreal, H2W 1R7 Quebec, Canada.

\section{INTRODUCTION}

Progression of the neuromuscular disease in subjects with Friedreich's ataxia leads to total respiratory failure. Three mechanisms contribute to the eventual fatal outcome: first, the severe scoliosis found in these patients leads to respiratory failure (Godfrey, 1970). Second, the neuromuscular dysfunction decreases the efficiency of the respiratory muscles (Greenberg and Edmonds, 1974). Third, in the late stage of the disease, these patients develop cardiac failure secondary to cardiomyopathy.

Among these 3 causes of respiratory failure, only scoliosis is preventable and treatable by means of orthopedic braces or corrective surgery, and therefore it is important to know the contribution of the scoliosis to the respiratory dysfunction.

This question remains unanswered in the few studies of pulmonary physiology in patients with Friedreich's ataxia (Thoren, 1964). The present study was designed to evaluate the pulmonary function of patients with Friedreich's ataxia; and to measure the contribution of scoliosis to respiratory dysfunction by comparison to subjects with a similar degree of scoliosis, but without associated neuromuscular disease.

\section{MATERIAL AND METHODS}

Twenty children and young adults known to fulfill the neurologic criteria of Friedreich's ataxia were studied in the pulmonary function laboratory of the Centre Hospitalier Universitaire de Sherbrooke. However, 6 patients had atypical spinocerebellar degeneration; 2 were reclassified as Charcot-Marie-Tooth syndrome. 2 Roussy-Levy syndrome and 1 remains unclassified.

For comparison, 13 control subjects with idiopathic thoracic scoliosis were studied. Any subject with a previous history of respiratory disorders (such as asthma, pneumonia, bronchitis), or neuromuscular disease, or with previous treatment for scoliosis was excluded from this control group.

All patients were tested in a seated position. The arm span was measured in order to calculate the nondeformed height used for the pulmonary function test predicted values as previously suggested for scoliotic patients (Hepper et al., 1965). The results were compared to the predicted values published for children and adults (Beaudry et al., 1967; Zapletal et al., 1969).

Residual volume (RV), functional residual capacity (FRC), vital capacity (VC) and total lung capacity (TLC), were measured with a Collins spirometer and by the helium dilution technique. Flows were studied with the spirometer for maximum mid-expiratory flow (MMEF) and force expiratory volume in one second $\left(F E V_{1.0}\right)$, but the flow volume curve for maximum flow at 50\% $(\mathrm{V} \max 50 \mathrm{vc})$ and $25 \%(\mathrm{~V} \max 25 \mathrm{vc})$ of VC was determined in the body phlebysmograph. Diffusing capacity of the lung for carbon monoxide (D $1_{\text {co }}$ ) was determined by the steady state method (Bates et al., 1956).

Arterial blood was sampled from the radial artery after instillation of local anaesthetic and blood gases were immediately measured with the I.L. 213 blood gas apparatus.

At the end of the study, the regression equation as a function of the degree of scoliosis of the 20 patients with Friedreich's ataxia was 
TABLE 1

Comparison Between Pulmonary Function Tests of Patients wi

\begin{tabular}{|c|c|c|c|c|c|c|c|c|c|c|c|c|c|c|}
\hline & & & & \multicolumn{2}{|c|}{ TLC } & \multicolumn{2}{|c|}{ VC } & FRC & & $\frac{\text { FRC }}{\text { TLC }}$ & & & $\frac{\mathrm{RV}}{\mathrm{TLC}}$ & MM \\
\hline$\stackrel{\text { : }}{\stackrel{\Xi}{*}}$ & 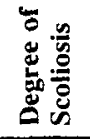 & 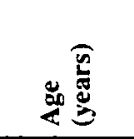 & 影 & 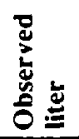 & 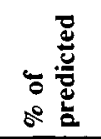 & 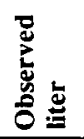 & 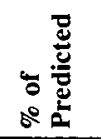 & 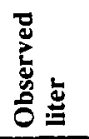 & 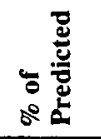 & 8 & 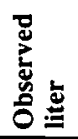 & 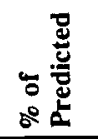 & 8 & 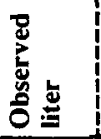 \\
\hline \multicolumn{2}{|c|}{ FRIEDREICH'S } & ATAXIA & & & & & & & & & & & & \\
\hline 4 & 24 & 15 & 154.7 & 4.78 & 197 & 3.21 & 125 & 2.64 & 165 & 55.2 & 1.54 & 196 & 32.2 & 2.08 \\
\hline 27 & 50 & 17 & 150.5 & 3.41 & 107 & 1.33 & 56 & 2.29 & 154 & 67.2 & 2.08 & 274 & 61.0 & 1.78 \\
\hline 28 & 78 & 14 & 150.5 & 1.58 & 56.8 & 0.91 & 44 & 0.99 & 76 & 62.7 & 0.63 & 93 & 33.9 & 1.03 \\
\hline 29 & 28 & 8 & 116.2 & 1.73 & 87 & 1.34 & 93 & 0.89 & 95 & 51.4 & 0.39 & 76 & 22.5 & 2.11 \\
\hline 25 & 52 & 22 & 178.4 & 3.65 & 78 & 2.31 & 65 & 2.14 & 100 & 58.6 & 1.34 & 129 & 36.7 & 0.95 \\
\hline 26 & 120 & 24.5 & 153.5 & 1.17 & 33 & 0.45 & 17 & 0.76 & 46 & 65.0 & 0.72 & 88 & 61.5 & 0.57 \\
\hline 30 & 13 & 12.5 & 162 & 3.43 & 87 & 2.62 & 88 & 1.62 & 88 & 47.2 & 0.81 & 90 & 23.6 & 3.12 \\
\hline 31 & 18 & 10 & 130 & 2.94 & 120 & 1.70 & 94 & 1.89 & 164 & 64.3 & 1.24 & 203 & 42.2 & 1.72 \\
\hline 32 & 18 & 13.5 & 145.8 & 4.06 & 129 & 2.85 & 122 & 2.17 & 147 & 53.4 & 1.21 & 161 & 29.8 & 3.23 \\
\hline 33 & 15 & 10 & 134.6 & 2.89 & 109 & 2.13 & 109 & 1.39 & 111 & 48.1 & 0.76 & 117 & 26.3 & 1.99 \\
\hline 5 & 0 & 32 & 150.8 & 3.83 & 153 & 2.97 & 116 & 1.71 & 110 & 44.6 & 0.86 & 100 & 22.5 & 2.64 \\
\hline 13 & 0 & 17 & 163.1 & 4.07 & 99 & 2.27 & 73 & 2.07 & 109 & 50.9 & 1.80 & 193 & 44.2 & 2.56 \\
\hline 34 & 32 & 16 & 165 & 7.21 & 172 & 4.80 & 110 & 4.08 & 146 & 56.6 & 2.41 & 254 & 33.4 & 4.20 \\
\hline 35 & 30 & 12 & 136.5 & 2.08 & 78 & 2.32 & 118 & 1.19 & 95 & 57.2 & 0.58 & 89 & 27.9 & 2.20 \\
\hline 36 & 68 & 18.5 & 175.9 & 4.07 & 91 & 2.27 & 67 & 2.24 & 108 & 55.0 & 1.78 & 178 & 43.7 & 1.57 \\
\hline 37 & 65 & 24 & 165.7 & 3.06 & 74 & 2.39 & 76 & 1.59 & 83 & 52.0 & 0.69 & 73.4 & 20.9 & 2.20 \\
\hline 38 & 60 & 28 & 158.4 & 2.27 & 49 & 1.20 & 36 & 1.56 & 61 & 69.0 & 1.06 & 79 & 46.9 & 0.46 \\
\hline 6 & 28 & 15 & 163.8 & 5.87 & 151 & 4.44 & 152 & 3.64 & 201 & 62.0 & 1.43 & 161 & 24.4 & 4.73 \\
\hline 7 & 10 & 13 & 176.5 & 5.37 & 118 & 3.84 & 112 & 2.86 & 136 & 53.3 & 1.53 & 139 & 28.5 & 3.88 \\
\hline 8 & 0 & 8.5 & 116.8 & 2.35 & 126 & 1.76 & 129 & 1.31 & 147 & 55.7 & 0.59 & 120 & 25.1 & 1.19 \\
\hline MEAN & 35.4 & 16 & 152.4 & 3.49 & 105.7 & 2.35 & 90.1 & 1.95 & 117.1 & 56.5 & 1.17 & 149.6 & 34.7 & 2.21 \\
\hline S.D. & 30.9 & 6.2 & 18.1 & 1.51 & 41.5 & 1.12 & 35.1 & 0.86 & 39.2 & 6.8 & 0.55 & 59.8 & 12.2 & 1.16 \\
\hline S.E. & 6.9 & 1.4 & 4.0 & 0.33 & 9.2 & 0.25 & 7.8 & 0.19 & 8.7 & 1.5 & 0.12 & 13.3 & 2.7 & 0.26 \\
\hline \multicolumn{15}{|c|}{ IDIOPATHIC SCOLIOSIS } \\
\hline LC & 26 & 16 & 160.9 & 5.34 & 134 & 3.51 & 117 & 3.15 & 170 & 59 & 1.83 & 201 & 34.3 & 3.63 \\
\hline SB & 32 & 17 & 158.5 & 3.71 & 97 & 2.72 & 94 & 2.09 & 117 & 56.3 & 0.99 & 112 & 26.7 & 3.02 \\
\hline FB & 30 & 21 & 165 & 5.01 & 94 & 3.75 & 97 & 2.72 & 94 & 54.3 & 1.26 & 87 & 25.1 & 2.93 \\
\hline $\mathrm{JM}$ & 18 & 19 & 155.4 & 4.44 & 98 & 3.28 & 98 & 2.36 & 97 & 53.2 & 1.16 & 97 & 26.1 & 4.81 \\
\hline FB & 34 & 16 & 152.5 & 3.19 & 91 & 2.46 & 93 & 1.57 & 96 & 49.2 & 0.73 & 89 & 22.9 & 2.52 \\
\hline $\mathrm{JB}$ & 35 & 14 & 156 & 4.58 & 123 & 3.76 & 134 & 2.01 & 115 & 43.9 & 0.82 & 95 & 17.9 & 4.09 \\
\hline $\mathrm{JL}$ & 30 & 18 & 160.4 & 4.66 & 118 & 3.44 & 116 & 2.46 & 134 & 52.8 & 1.22 & 135 & 26.2 & 3.40 \\
\hline SR & 46 & 13 & 157.5 & 3.38 & 91 & 2.54 & 91 & 1.86 & 107 & 55.0 & 0.84 & 98 & 24.9 & 2.25 \\
\hline $\mathrm{JL}$ & 13 & 18.5 & 164.3 & 5.36 & 101 & 4.23 & 109 & 2.40 & 83 & 44.8 & 1.13 & 78 & 21.1 & 2.70 \\
\hline LL & 32 & 12 & 141.6 & 2.81 & 92 & 2.47 & 109 & 1.0 & 70 & 35.6 & 0.34 & 46 & 12.1 & 2.78 \\
\hline SB & 50 & 16 & 166.5 & 3.56 & 85 & 2.69 & 84 & 1.96 & 100 & 55.1 & 0.87 & 91 & $|24.4|$ & 2.40 \\
\hline $\mathrm{CQ}$ & 20 & 14 & 153.5 & 3.73 & 100 & 3.26 & 116 & 1.55 & 89 & 41.2 & 0.47 & 55 & 17.2 & 2.48 \\
\hline $\mathrm{CS}$ & 90 & 15 & 151 & 2.80 & 83 & 2.15 & 85 & 1.24 & 78 & 44.3 & 0.61 & 82 & 21.8 & 1.38 \\
\hline MEAN & 35 & 16.1 & 157.1 & 4.04 & 100.5 & 3.09 & 103.3 & 2.02 & 103.8 & 49.6 & 0.94 & 97.3 & 23.1 & 2.95 \\
\hline S.D. & 19.4 & 2.5 & 6.7 & 0.90 & 15.2 & 0.63 & 14.8 & 0.60 & 26.2 & 7.0 & 0.39 & 38.3 & 5.4 & 0.87 \\
\hline S.E. & 5.3 & 0.7 & 1.8 & 0.25 & 4.2 & 0.17 & 4.1 & 0.16 & 7.2 & 1.9 & 0.10 & 10.6 & 1.5 & 0.24 \\
\hline$p$ & N.S. & N.S. & N.S. & & N.S. & & N.S. & & N.S. & 0.01 & & 0.02 & 0.001 & \\
\hline
\end{tabular}


Friedreich's Ataxia and Idiopathic Scoliosis

\begin{tabular}{|c|c|c|c|c|c|c|c|c|c|c|c|c|}
\hline & \multirow{2}{*}{$\begin{array}{c}\frac{F E V_{1}}{V C} \\
\therefore\end{array}$} & \multicolumn{2}{|c|}{$V \max 50 \mathrm{VC}$} & \multicolumn{2}{|c|}{$V \max 25 \mathrm{VC}$} & \multicolumn{2}{|c|}{ DLCO } & \multicolumn{3}{|l|}{ DLCO } & pHa & $\left(\mathrm{HCO}_{3}\right)_{2}$ \\
\hline & & 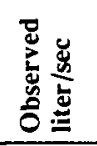 & 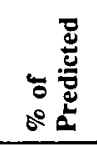 & 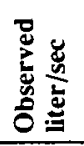 & 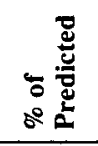 & 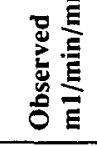 & 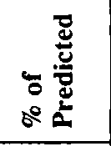 & 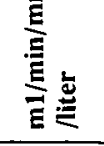 & 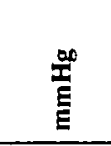 & 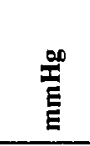 & & 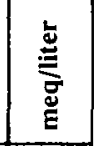 \\
\hline 4 & 81 & & & & & & & & 90.8 & 38.5 & 7.44 & 22.2 \\
\hline 0 & 98 & & & & & 7.89 & 47 & 94.5 & 94.5 & 24.7 & 7.42 & 15.6 \\
\hline \begin{tabular}{l|l}
0.4 \\
\end{tabular} & 99 & 0.8 & 29 & 0.4 & 26 & 7.60 & 54 & 7.67 & 74 & 29.2 & 7.40 & 17.5 \\
\hline 3 & 100 & 2.50 & 76 & 1.5 & 66 & 7.78 & 92 & 8.74 & 85 & 29.3 & 7.41 & 18 \\
\hline 1 & 73 & & & & & 12.77 & 53 & 6.68 & 76.4 & 29.5 & 4.43 & 19.4 \\
\hline 7 & 99 & & & & & 4.91 & 27 & 6.44 & & & & \\
\hline 2 & 95 & 3.9 & 103 & 2.4 & 112 & 11.83 & 57 & 7.30 & 76 & 29.5 & 7.36 & 16.2 \\
\hline 8 & & 2.3 & 100 & 1.3 & 100 & 14.95 & 124 & 7.91 & 90.8 & 28.8 & 7.44 & 19 \\
\hline 0 & 90 & 3.4 & 133 & 2.0 & 118 & 13.10 & 80 & 6.04 & 86.5 & 27.0 & 7.44 & 18 \\
\hline 3 & 87 & 3.6 & 138 & 2.6 & 185 & 6.03 & 45 & 4.34 & & & & \\
\hline 1 & & 3.5 & 107 & 2.1 & 120 & 15.33 & 86 & 8.97 & 92 & 32 & 7.43 & 21 \\
\hline 4 & 100 & & & & & 15.04 & 70 & 7.27 & 82.5 & 32.5 & 7.35 & 17.5 \\
\hline 2 & 82 & & & & & 23.49 & 107 & 3.50 & 85 & 34.5 & 7.40 & 21 \\
\hline 1 & 86 & 2.5 & 96 & 1.1 & 85 & 15.67 & 120 & 13.7 & & & & \\
\hline 7 & 73 & & & & & 9.65 & 41 & 4.31 & 69 & 33 & 7.41 & 20.5 \\
\hline 4 & & & & & & 9.58 & 44 & 6.03 & & & & \\
\hline 4 & 55 & & & & & 7.91 & 48 & 3.25 & 69 & 35 & 7.40 & 21.4 \\
\hline 6 & 94 & 5.5 & 141 & 3.5 & 171 & 19.60 & 97 & 5.39 & 81.2 & 29.5 & 7.42 & 18.5 \\
\hline 7 & 95 & 4.6 & 107 & 2.9 & 116 & 14.79 & 62 & 5.17 & 81 & 31.3 & 7.40 & 19.3 \\
\hline 3 & 79 & 1.8 & 120 & 0.8 & 100 & 15.75 & 220 & 12.02 & 76 & 29 & 7.41 & 18 \\
\hline $\mid 0.3$ & 87.4 & 3.1 & 104.6 & 1.8 & 109 & 12.29 & 77.6 & 6.74 & 81.8 & 30.8 & 7.41 & 18.9 \\
\hline 2.8 & 12.4 & 1.3 & 31.6 & 0.9 & 43.8 & 4.84 & 44.4 & 2.77 & 7.9 & 3.3 & 0.02 & 1.8 \\
\hline 7.3 & 3.0 & 0.3 & 9.5 & 0.2 & 13.2 . & 1.11 & 10.1 & 0.63 & 1.9 & 0.8 & & 0.4 \\
\hline 4 & 94 & 4.9 & 128 & 3.0 & 142 & 6.28 & 30.1 & 2 & 83 & 24.8 & 7.41 & 15.4 \\
\hline 2 & 94 & 4.1 & 110 & 2.2 & 110 & 8.08 & 40.4 & 3.86 & 84 & 27.5 & 7.39 & 16.0 \\
\hline 8 & 89 & 4.0 & 80 & 2.0 & 66 & 13 & 68.78 & 4.77 & 93.5 & 24 & 7.42 & 15.2 \\
\hline 6 & 94 & 5.6 & 119 & 3.4 & 117 & 10.58 & 57.81 & 4.48 & 89 & 30.5 & 7.46 & 21.2 \\
\hline 5 & 93 & 3.1 & 92 & 1.4 & 74 & 10.76 & 36.73 & 4.30 & 95 & 26 & 7.46 & 18.4 \\
\hline 5 & 90 & 4.5 & 125 & 2.4 & 120 & 14.59 & 75.20 & 7.25 & 86 & 32.3 & 7.41 & 20.0 \\
\hline 9 & 88 & 4.0 & 105 & 2.4 & 114 & 14.04 & 68.15 & 5.70 & 93 & 30.7 & 7.35 & 15.4 \\
\hline 8 & 87 & 2.6 & 72 & 1.2 & 60 & 12.38 & 63.48 & 6.65 & 95 & 30 & 7.32 & 14.9 \\
\hline 7.5 & 77 & 3.1 & 64 & 1.6 & 53.3 & 14.73 & 77.93 & 6.13 & 82 & 30 & 7.40 & 18.5 \\
\hline 8 & 89 & 3.4 & 117 & 2.0 & 125 & 11.54 & 74.40 & 11.54 & 92.5 & 31.5 & 7.37 & 17.8 \\
\hline 8 & 89 & & & & & 9.32 & 43 & 4.76 & & & & \\
\hline 9 & 84 & & & & & 12.22 & 63 & 7.88 & & & & \\
\hline 8 & 76 & & & & & 6.50 & 37 & 5.24 & & & & \\
\hline 0.9 & 88 & 3.9 & 101.2 & 2.1 & 98.1 & 10.77 & 56.61 & 5.73 & 89.3 & 28.7 & 7.39 & 17.3 \\
\hline 8.1 & 5.9 & 0.9 & 22.8 & 0.6 & 31.5 & 2.09 & 16.97 & 2.32 & 5.1 & 2.9 & 0.04 & 2.2 \\
\hline 6.4 & 1.6 & 0.2 & 7.2 & 0.2 & 9.9 & 0.85 & 4.68 & 0.64 & 1.6 & 0.9 & 0.01 & 0.7 \\
\hline S. & N.S. & & N.S. & & N.S. & & N.S. & N.S. & $<0.01$ & N.S. & N.S. & N.S. \\
\hline
\end{tabular}


determined for RV, VC, FRC, TLC,

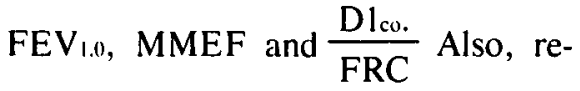
gression equations were obtained for the subjects with idiopathic scoliosis. For the latter, however, the data of the present 13 patients could be combined with the data published by Weber et al. (1975) for 28 patients with the same condition chosen by the same criteria. The MMEF curve was determined only
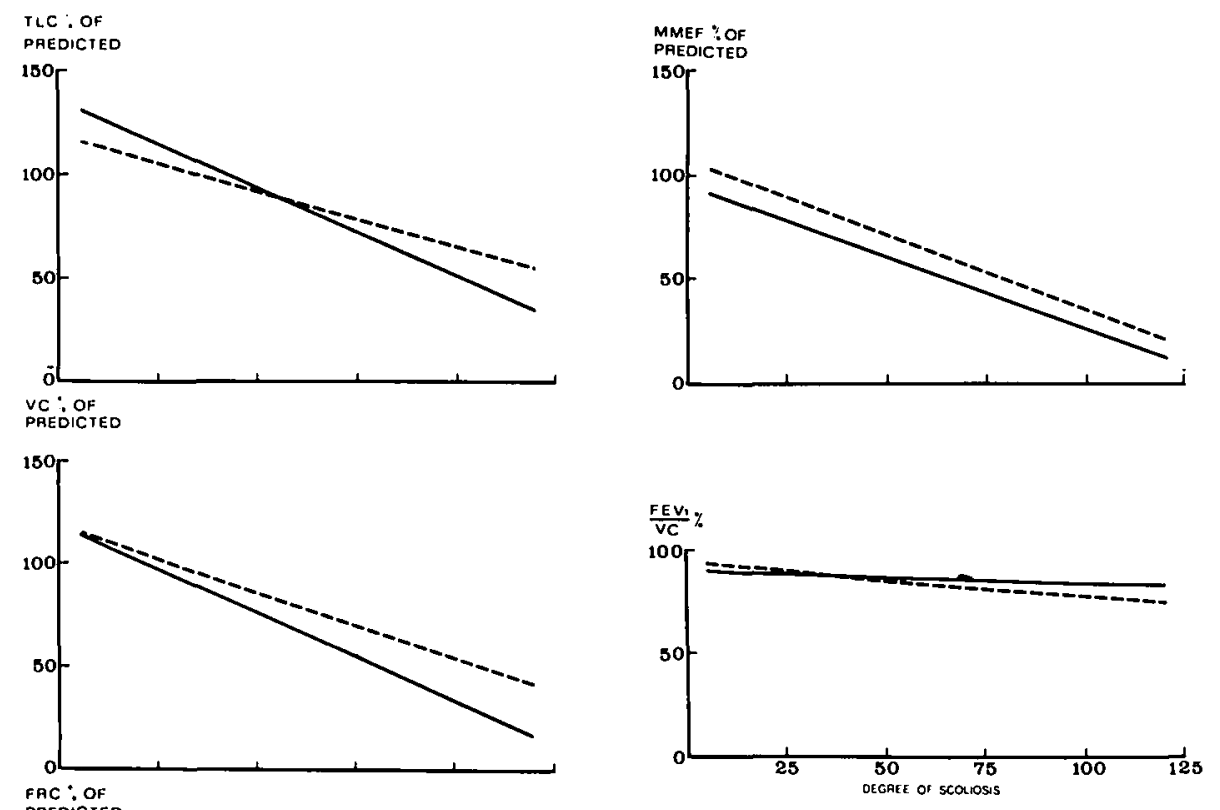

PREDICTED
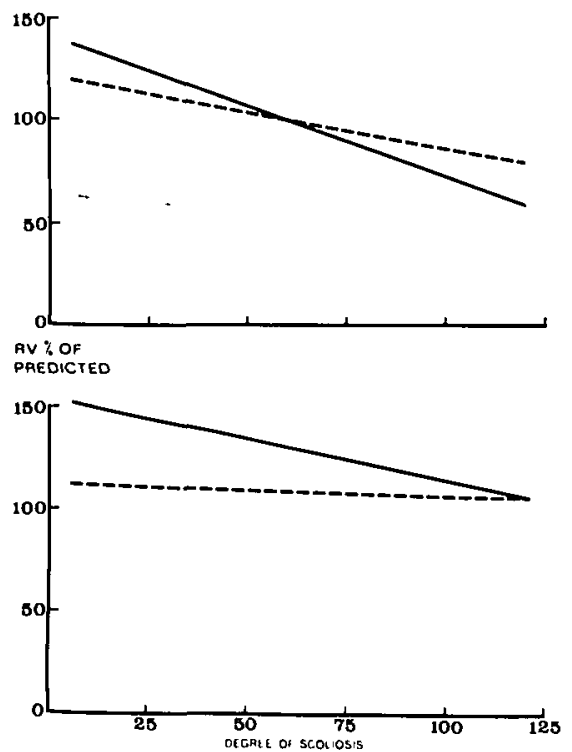

Figure 1 - Changes in lung volume with progression of scoliosis in subjects with Friedreich's ataxia (solid line) and idiopathic scoliosis (broken line). for the 13 subjects with idiopathic scoliosis.

\section{RESULTS}

Patients with Friedreich's ataxia

The mean age of this group of 11 females and 9 males was 16.0 years with a mean arm span of $152.5 \mathrm{~cm}$. The degree of the thoracic scoliosis was $35.5^{\circ}$.

Lung volume: VC was $90 \%$ and TLC $105 \%$ of predicted value. However, there was an important increment in

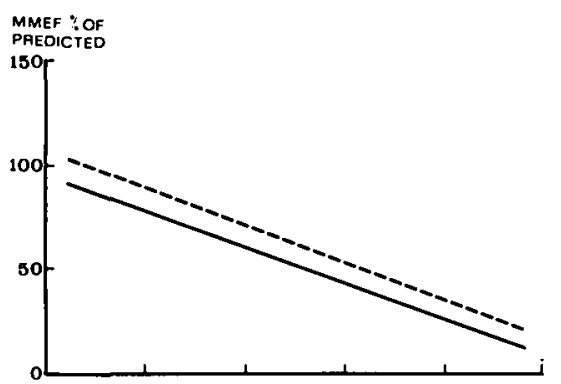

Figure $2-$ Changes in flow rate, maximum mid expiratory flow (MMEF) and forced expiratory volume in one second $\frac{\left(F E V_{1.0}\right)}{V C}$ with scoliosis in subjects with Friedreich's ataxia (solid line) and idiopathic scoliosis (broken line).

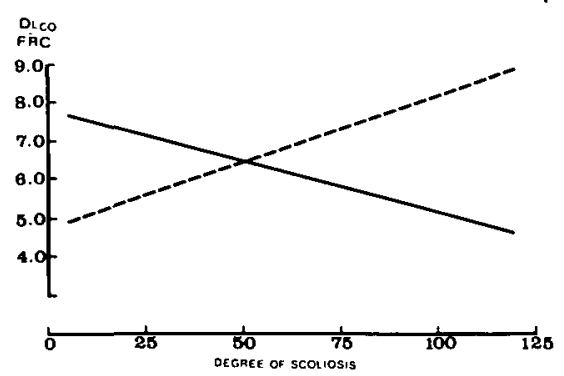

Figure 3 - Changes in diffusing capacity per liter of functional residual capacity $\frac{(\mathrm{DLco})}{\mathrm{FRC}}$ in $\mathrm{ml} / \mathrm{mm} / \mathrm{mm} \mathrm{Hg} / \mathrm{l}$ with scoliosis in subjects with Friedreich's ataxia (solid line) and idiopathic scoliosis (broken line).
RV and FRC which were respectively $140.6 \%$ and $117 \%$ of the predicted value (Table 1). The ratios $\frac{\mathrm{RV}}{\mathrm{TLC}}$ and $\frac{\text { FRC }}{\text { TLC }}$ were increased to $34.7 \%$ and TLC $56.5 \%$.

Flow: The FEV $\mathrm{F}_{10}$ sec. was normal being $87.4 \%$ of the force vital capacity, but the MMEF was decreased to $70 \%$ of the predicted value. Vmax 25 $\mathrm{vc}$ and $\mathrm{V} \max 50 \mathrm{vc}$ were normal at $109.1 \%$ and $104.6 \%$ of predicted values. However, these two assessments were done only in the less deformed patients who could enter into the body phlebysmograph.

Diffusing capacity: D lo was $77.7 \%$ of predicted value. As Dlco varies with changes in FRC, the ratio $\frac{D 1_{c o}}{F R C}$ was calculated to be also decreased at 6.75 which was $59.7 \%$ of the normal value reported (Weng and Levison, 1969).

Blood gases. The mean $\mathrm{Pa}_{02}$ was moderately low at 81.8 torr (torr is $\mathrm{mm}$ of HG equivalent.) and for 9 of the 16 patients, $\mathrm{Pa}_{02}$ was below 85 torr. $\mathrm{Pa}_{\mathrm{CO} 2}$ was decreased to 30.8 torr with a normal $\mathrm{pH}_{\mathrm{u}}$ of 7.411 , suggesting a compensated respiratory alkalosis with a bicarbonate decrease to 18.9 milliequivalent per liter of blood.

Comparison of patients with Friedreich's ataxia to subjects with idiopathic scoliosis.

The control group of 13 (all female) children and young adults with idiopathic scoliosis was similar regarding the mean age, mean arm span and mean degree of scoliosis (Figure 1). Sex difference does not introduce a noticeable bias, since the results are expressed as percent of predicted value specifically for males or females.

In the lung volumes, RV and the ratios of $\frac{R V}{T L C}$ and $\frac{\text { FRC }}{\text { TLC }}$ were statistically increased in the group of patients with Friedreich's ataxia.

Flows as measured by MMEF, FEV ${ }_{1.0}$ sec $\cdot V \max 25$ vc were not different in the 2 groups. The decrease in the diffusing capacity reported to the FRC for the 2 groups as $\frac{D 1_{\text {co }}}{F R C}$ is 
similar. It is interesting to note the difference in the Paoz which is normal in scoliotic subjects and low in the Friedreich's ataxia subjects.

As is shown in Figure 1, the degree of scoliosis causes a loss in TLC, VC and FRC. The decrease in lung volume is more pronounced in patients with Friedreich's ataxia. In idiopathic scoliosis, RV is independent of scoliosis, but it is dependent of the degree of scoliosis in the ataxia patients. In both groups of patients, the MMEF decreased with scoliosis probably secondary to a loss in lung volume (Figure 2). As the scoliosis progresses, the lung volume changes and the ratio $\frac{D 1_{c o}}{F R C}$ drops for patients with Friedreich's ataxia, but it improves for control patients with idiopathic scoliosis (Figure 3).

\section{DISCUSSION}

The present study confirms the only extensive spirometric study in patients with Friedreich's ataxia in that a similar fall in VC and TLC and elevated RV and FRC were found. These authors have held that the neuromuscular impairment rather than the effects of chest deformity were responsible for these pulmonary changes (Thoren, 1964).

To measure the effect of the scoliosis itself in the presence of neuromuscular disease, the pulmonary changes of control subjects with idiopathic scoliosis were compared with those of patients with simultaneous progression of a neuromuscular defect and scoliosis (Friedreich's ataxia patients).

From the analysis of the curves in Figure 1, one may conclude that the scoliosis itself causes most of the respiratory difficulty in patients with Friedreich's ataxia. Scoliosis leads to a similar decrease in lung volume; VC, FRC and TLC drop in both groups, but the decrease is more important in patients with Friedreich's ataxia. However, the RV which in scoliosis subjects is known to be independent of the degree of scoliosis (Weng and Levison, 1969), changes with progression of the sco-

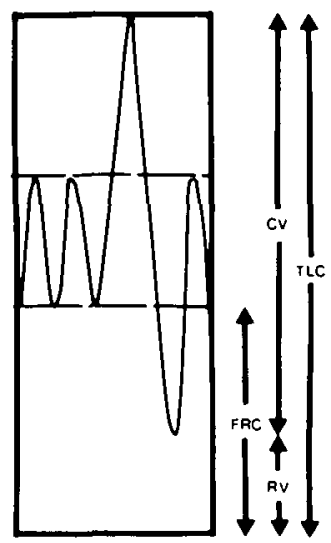

NORMAL

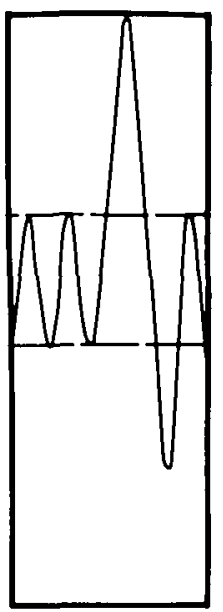

EARLY CHANGES IN PATIENTS WITH FA

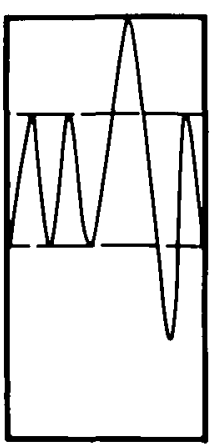

LATE CHANGES IN PATIENTS WITH FA

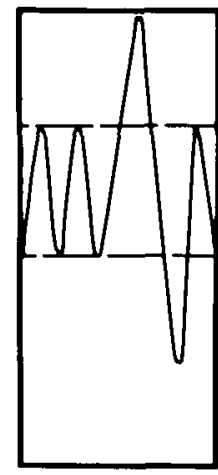

LATE CHANGES IN PATIENTS WITH SCOLIOSIS

Figure 4 - Comparison in lung volume between normal subjects, patients with early or late Friedreich's ataxia and patients with severe idiopathic scoliosis.

liosis in patients with Friedreich's ataxia; in the early stages, the RV is increased suggesting a loss of thoracic wall recoil, but with further progression of the scoliosis, RV decreases. The increase RV and FRC cannot be explained by an obstructive pulmonary disease since flow rate, as MMEF, FEV 1.0, Vmax 50 $\mathrm{vc}, \mathrm{V} \max 25 \mathrm{vc}$, are normal.

It was found in this study and in other investigations (Thoren, 1964; Weber et al., 1975), that the pulmonary function in scoliotic patients resembles a normal subject whose chest is strapped. Two slight differences are noted in patients with Friedreich's ataxia. First, at the beginning of the disease, the elastic forces applied to the chest are weaker than they are for a normal subject and therefore lung volume is increased. Second, in the advanced stage, the elastic corset is stronger for the Friedreich's ataxia patient than for the scoliotic control and lung volume is reduced (Figure 4).

The evolution of pulmonary function in Friedreich's ataxia patients treated orthopedically for their scoliosis has yet to be determined. From our results, it appears appropriate to treat the scoliosis of such patients and to test their pulmonary physiology in the postoperative period to assess the benefit of this approach.

\section{ACKNOWLEDGMENT}

We are grateful to Dr. C. Léger, Radiologist, and to Dr. Ho, statistician for their contribution to this study. These investigations were funded in part by L'Association Canadianne de l'Ataxie de Friedreich.

\section{REFERENCES}

BATES, D. V., BOUCOT, N. G.. and DORMER, A. E. (1955). The pulmonary diffusing capacity in normal subjects. J. Physiol., 129. 237-252.

BEAUDRY, P. H., WISE, M. B., and SEELEY, J. E. (1967). Respiratory gaz exchange at rest and during exercise in normal and asthmatic children. Amer. Rev. Resp. Dis., 95, 248-254.

GODFREY, S. (1970). Respiratory and cardiovascular consequences of scoliosis. Respiration, 27, suppl., 67-76.

GREENBERG, M., and EDMONDS, J. (1974). Chronic respiratory problems in neuromyopathic disorders. Pediat. Clin. N. Anier., 21, 927-234.

HEPPER, N. G. G., BLACK, L. F., and FOWLER, W. S. (1965). Relationship of lung volume to height and arm span in normal subjects and in patients with spinal deformity. Amer. Rev. Resp. Dis., 91, 356-

THOREN, C. (1964). Cardiomyopathy in Friedreich's ataxia. Acta Paediat. (Stockholm), 53, suppl. 153, 1-132.

WEBER, B., SMITH, J. P., BRISCOE, W. A., FRIEDMAN, S. A., and KING. T. K. C. (1975). Pulmonary function in asymptomatic adolescents with idiopathic scoliosis. Amer. Rev. Resp. Dis., 111, 389-397.

WENG, T. R., and LEVISON, H. (1969). Standard of pulmonary function in children. Amer. Rev. of Resp. Dis., 99, 879-894.

ZEPLETAL, A., MOTOYAMA, E. K., VAN DE WOESTIJNE, K. P., HUNT, V. R., and BOUHUYS, A. (1969). Maximum expiratory flow volume curves and airway conductance in children and adolescent. J. Appl. Physiol., 26, 308-316. 